\title{
The use of continuous perineural catheters and other practices to optimize regional anesthesia in COVID-19 patients
}

\author{
John J. Finneran IV, MD (1) - Engy T. Said, MD • Brian P. Curran, MD • \\ Rodney A. Gabriel, MD, MAS (Clinical Research)
}

Received: 8 June 2020 / Accepted: 8 June 2020 /Published online: 12 June 2020

(C) Canadian Anesthesiologists' Society 2020

To the Editor,

As anesthesiologists, we are on the front line of the fight against coronavirus disease (COVID-19), whether in the intensive care unit, operating room, or elsewhere in the hospital. Given the highly contagious nature of the severe acute respiratory syndrome coronavirus 2 (SARS-CoV-2) virus via contact, droplets, and aerosols, it is critically important for anesthesiologists to have proper personal protective equipment (PPE) and for healthcare systems to create protocols to minimize exposure. ${ }^{1}$ In the operating room, regional anesthesia has the potential to allow providers to avoid the aerosol generation associated with general anesthesia and its requisite bag mask ventilation, airway suctioning, and endotracheal intubation. ${ }^{2}$ Regional anesthesia, therefore, has the potential to decrease SARS$\mathrm{CoV}-2$ spread to healthcare workers, in addition to the many other benefits nerve blocks offer to surgical patients. ${ }^{3}$ Based on our experience performing regional anesthesia in COVID-19 patients, we recommend performing all blocks in the patient's isolation room before transportation to the perioperative area. Additionally, we recommend continuous peripheral nerve blocks for all COVID-19 patients expected to have multiple surgeries or significant prolonged postoperative pain.

Some authors have recommended bringing COVID-19 patients to the operating room for the nerve block to be performed, waiting for the block to fully set-up, and then checking the block with ice prior to proceeding with surgery. ${ }^{2}$ We feel that this not only unnecessarily increases

J. J. Finneran IV, MD ( $₫)$ · E. T. Said, MD .

B. P. Curran, MD - R. A. Gabriel, MD, MAS (Clinical Research)

Department of Anesthesiology, University of California San

Diego, San Diego, CA, USA

e-mail: jfinneran@health.ucsd.edu the operating room time but also potentially increases exposure to personnel in the operating room without providing significant benefit. In contrast, our practice is to perform blocks in the patient's own isolation room using standard monitors ${ }^{4}$ and limited sedation with intravenous midazolam and fentanyl, allowing us to assess adequacy of the block and then proceed to the operating room. This practice offers the benefits of ensuring the block will work adequately for surgery while minimizing time in the operating room and exposure of the perioperative staff. When performing blocks on COVID-19 patients, the most experienced regional anesthesiologist performs the block and should utilize the Centers for Disease Control and Prevention recommended PPE. ${ }^{5}$ This ideally is done without anyone else in the room in order to limit the potential SARS-CoV-2 exposure. If assistance is needed with catheter placement, sedation, or monitoring, we recommend that this be provided by a capable assistant (e.g., regional anesthesia fellow) also wearing full PPE.

Single injection nerve blocks only last hours, while continuous peripheral nerve blocks can last days or longer. ${ }^{3}$ In addition to the conventional benefits of improved analgesia and decreased opioid consumption, continuous nerve blocks allow for repeated trips to the operating room without additional exposure for the regional anesthesiologist. Alternatively, with a well-functioning continuous peripheral nerve block, debridements or other small procedures that would normally be done in the operating room may be done bedside. This further limits the exposure of operating room personnel. Furthermore, given the improved analgesia associated with continuous peripheral nerve blocks, these patients may be discharged and returned to quarantine earlier than if a single injection nerve block is utilized. It is, therefore, our practice to place perineural catheters for all appropriate COVID-19 surgical 
patients receiving regional anesthesia. These practices have allowed us to provide the benefits of regional anesthesia to COVID-19 patients with no viral transmission to the regional anesthesiology staff.

Disclosures Dr. Finneran's institution has received funding and/or product for his research from Ferrosan Medical Devices, Myoscience, Epimed, SPR Therapeutics, and InfuTronix. Dr. Said's institution has received funding and/or product for her research from Ferrosan Medical Devices, Myoscience, Epimed, SPR Therapeutics, and InfuTronix. Dr. Gabriel's institution has received funding and/or product for his research from Ferrosan Medical Devices, Myoscience, Epimed, SPR Therapeutics and InfuTronix.

\section{Funding statement None.}

Editorial responsibility This submission was handled by Dr. Hilary P. Grocott, Editor-in-Chief, Canadian Journal of Anesthesia.

\section{References}

1. Li $Q$, Guan $X, W u P$, et al. Early transmission dynamics in Wuhan, China, of novel coronavirus-infected pneumonia. N Engl J Med 2020; 382: 1199-207.

2. Lie SA, Wong SW, Wong LT, Wong TG, Chong SY. Practical considerations for performing regional anesthesia: lessons learned from the COVID-19 pandemic. Can J Anesth 2020; 67: 885-92.

3. Ilfeld BM. Continuous peripheral nerve blocks: An update of the published evidence and comparison with novel, alternative analgesic modalities. Anesth Analg 2017; 124: 308-35.

4. Dobson G, Chow L, Flexman A, et al. Guidelines to the practice of anesthesia - revised edition 2019. Can J Anesth 2019; 66: 75-108.

5. Centers for Disease Control and Prevention. Using Personal Protective Equipment (PPE). Available from URL: https://www. cdc.gov/coronavirus/2019-ncov/hcp/using-ppe.html (accessed June 2020).

Publisher's Note Springer Nature remains neutral with regard to jurisdictional claims in published maps and institutional affiliations. 